\title{
Load Distribution Factors for Hollow Core Slabs with In-situ Reinforced Concrete Joints
}

\author{
Jong-Young Song, ${ }^{1)}$ Kim S, Elliott, ${ }^{2)}$ Ho Lee, ${ }^{3)}$ and Hyo-Gyoung Kwak ${ }^{4)}$
}

(Received March 16, 2009, Revised May 6, 2009, Accepted May 7, 2009)

\begin{abstract}
This paper provides the engineer with a simple design method dealing with situations arise where in-situ reinforced concrete joints are cast between hollow core units. Using finite element method, hollow core slabs with wide in-situ RC joints under point load and line loads are analysed. In addition, some important behavioural characteristics of the floor slab subjected to line and point loads are investigated. In-situ reinforced concrete joint causes reduction of load distribution for remote units because distance to the remote units from the point of load is increased, while the portion of load distribution carried by loaded unit increases. Also, it was turned out load distribution factors for point load and line loads are almost same. Finally, we suggest a simple analytical method, which can determine load distribution factors using normalized deflections by regression analysis for design purposes.
\end{abstract}

Keywords: hollow core unit, load distribution factors, in-situ joint.

\section{Introduction}

Precast concrete flooring offers an economic and versatile solution to suspended floors in any type of building. There is a wide range of precast flooring types available to give a structural and economic solution for spans from 4 to $25 \mathrm{~m}$, and depths from $100 \mathrm{~mm}$ to $1 \mathrm{~m}$. The most common of these being hollow core units (hcu), for which a 1,200 mm wide unit is shown in Fig. 1. In Europe alone the annual production of hcu is about 25 m sq.m.

The floors are designed and constructed as one-way spanning in the direction of the hollow cores. The units are not provided with transverse reinforcement either within the element itself or in the joints between the units. The individual units are keyed along their edges using site filled using flowable concrete/mortar (grade B20 min.) to form a shear key without moment transfer. The shear key permits the transverse distribution of reactions from line loads (e.g. masonry walls) acting parallel to the span of the floor, and also localised point loads. Because the units are often used without a cast insitu structural topping, the lateral load distribution relies entirely on the shear key. In order to complete the design of the entire floor slab it is necessary to determine the proportion of load distributed to adjacent units.

\footnotetext{
${ }^{1)}$ KCI Member, Samsung C\&T Corporation, Civil Division, Seoul 137-857, Korea. E-mail: jongyoung.song@samsung.com

${ }^{2)}$ Univ. of Nottingham, Dept. of Civil Engineering, Nottingham, UK.

${ }^{3)}$ Kyungpook National University, School of Arch. Eng., Sangju 702-842, Korea.

${ }^{4)}$ KCI Member, Dept. of Civil and Env. Eng., KAIST, Daejeon 305-338, Korea.

Copyright (c) 2009, Korea Concrete Institute. All rights reserved, including the making of copies without the written permission of the copyright proprietors
}

A line load produces a shear reaction in the longitudinal edge of the adjacent units, and this induces bending, shear and torsion in the next slab. See Fig. 2. The capacity of the hcu to carry torsion is limited by the tensile capacity of the concrete. The magnitude of the shear reaction depends on the torsional stiffness and the longitudinal and transverse stiffness of all the adjacent units, low stiffness resulting in low load sharing. The deflected profile of the total floor slab is computed using finite strips and differential analysis. In this work a computer program SAP $2000^{1}$ was used such that the cross-section of each floor element is considered as a rectangular plate element and the voids are ignored because its influence to load distribution between hollow core units is negligible.

The result of the analysis leads to the well established conclu$\operatorname{sion}^{2,3}$ that line and point loads may be distributed over an effective width equal to the total width of about five $1.2 \mathrm{~m}$ wide precast units. These are given by the $\alpha$ factors in Fig. $3{ }^{4}$ The data shows that for edge elements, e.g. adjacent to a large void or free edge, only three $1.2 \mathrm{~m}$ wide units contribute significantly in carrying the load (a similar analysis could be carried out for $600 \mathrm{~mm}$ wide units).

Situations arise where insitu reinforced concrete strips are cast between hollow core units, either to make up gaps at the edges of floor slabs, or to provide a ring beam to carry horizontal diaphragm forces through the precast floor plate. As shown in Fig. 4 , the strips are known to be up to $500 \mathrm{~mm}$ wide and can occur at frequent intervals, e.g. at $2.4 \mathrm{~m}$ or $3.6 \mathrm{~m}$ spacing. The insitu strips will inevitably have an influence on the $\alpha$ factors for the following reasons:

- the strength (typically grade B20) and Young's modulus (typically $25 \mathrm{GPa}$ ) of the insitu concrete is much lower than that of the hcu,

- the flexural and torsional stiffness of the insitu strip will be 


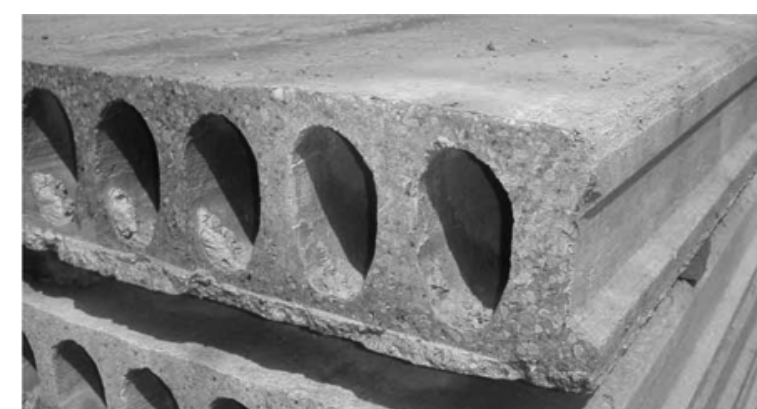

Fig. 1 The keyed edge profile of the hollow core units.

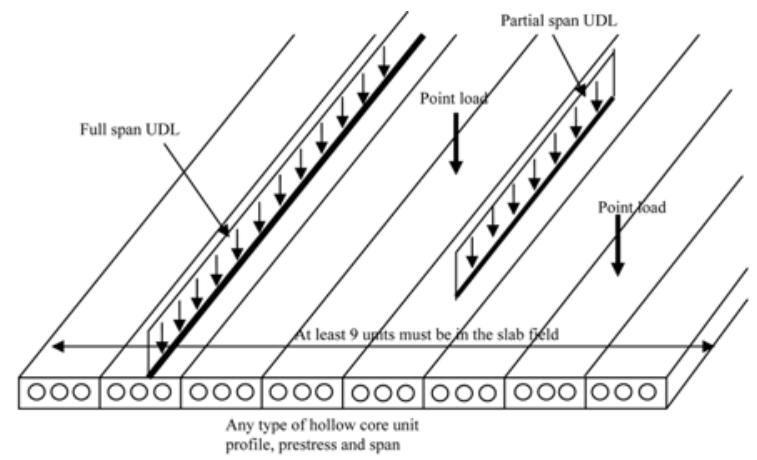

(a) Definition of precast hollow core slab field and the type of line and point loads

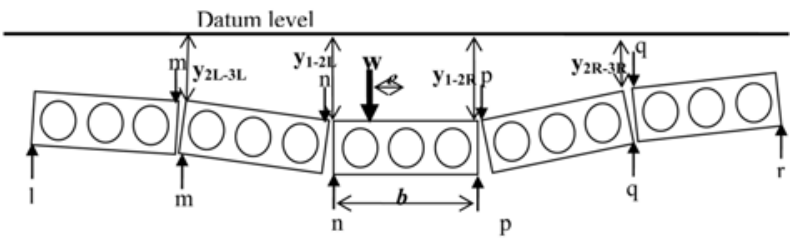

(b) Structural mechanism for lateral load spreading

Fig. 2 Definition of precast hollow core slab.

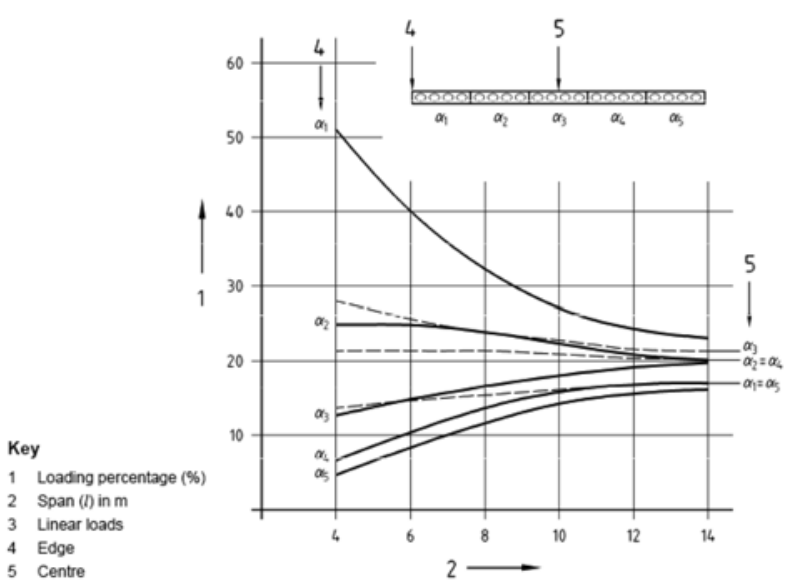

Fig. 3 Lateral load distribution factors for linear line loads in EN1168. ${ }^{4}$

totally different to that of the hcu,

- the distance to the remote hcu from the point of load will be increased, thus reducing the distribution factors there.

In order to provide the distribution factors for hcu slabs constructed with insitu strips, this paper presents the distribution factors,

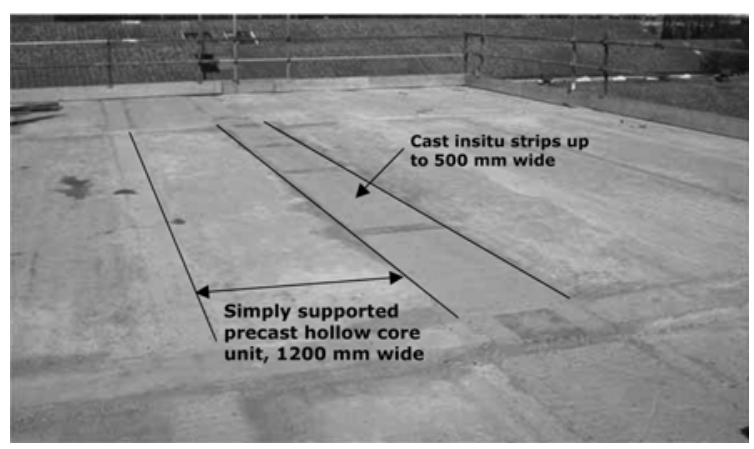

Fig. 4 The case of hollow core units cast with wide insitu strips.

in addition to showing some additional behavioural characteristics of the floor slab subjected to line and point loads.

\section{Load distribution factors by finite element method}

In general, the amount of load distribution for hollow core units under concentrated load or linear line loads can be calculated on the basis of assumption that joints cannot transmit bending moment but can transmit shear forces. Van Acker ${ }^{3}$ provided an analytical method on the basis of linear analysis of the longitudinal and transverse deformation of continuous slab elements under a concentrated loading. Stanton ${ }^{2}$ proposed distribution widths for bending, shear and deflection of precast decks subjected to concentrated loads using the finite strip method. Venkateswarlu et al. ${ }^{5}$ also produced moment, shear and deflection coefficients for lateral load distribution based on orthotropic plate theory. Recently, the finite element method has been widely used in the analysis of decks with variable slab thickness and slab orthotropy including stiffness discontinuity. ${ }^{6}$ In this paper, hollow core slabs with wide in-situ RC joints under concentrated loads and linear line loads are analysed using the finite element method.

It was found that transverse load distribution occurs mainly over five elements for central loadings and three elements for edge loadings. ${ }^{7}$ The effective distribution width is calculated as Eq. (1) based on comparative computations of maximum moment for the hcu alone and slabs with grouted joints. Applying this equation to the finite element model adopted in this study, effective distribution width is 4.54 units for central loadings and 2.54 units for edge loadings, which shows good agreement with FIP values. ${ }^{7}$

$$
b_{\text {eff }}=0.125 b / \alpha
$$

where $b_{\text {eff }}$ is effective distribution width and $\mathrm{b}$ is unit width; $\alpha$ and 0.125 are the bending coefficients for slabs with grouted joints and for unit alone, respectively; i.e., maximum moment is $\alpha w L^{2}$ and $0.125 w L^{2}$ for slabs with grouted joints and for unit slab, respectively and $\mathrm{w}$ is uniform load; $\mathrm{L}$ is the span length of slab unit.

To verify the approach adopted in this study, an elastic analysis using common finite element software SAP $2000^{1}$ for slab system consisted of seven grouted hollow core units is carried out under concentrated loading and line loading. To consider the 
effect of load distribution over several units, seven units with grouted joints are used in this study.

Each hcu having 1,200 mm width and $200 \mathrm{~mm}$ thickness is modelled either by isotropic or orthotropic plate element dependant on material property and the longitudinal joints width of $30 \mathrm{~mm}$, that is regarded as a structural hinge. These joints are modelled as structural hinge capable of finite moment and full shear transfer by assigning zero transverse bending stiffness. Fig. 5 shows mid-span deflections for seven units subjected to a line load of $100 \mathrm{~N} / \mathrm{mm}$ acting at the edge of the slabs (Fig. 5(a)) or in the centre of the slabs (Fig. 5(b)).

Once the profile of moment or deflection is obtained, the load distribution factors for moment or displacement are calculated using Eqs. (2) and (3), respectively. In this case, the flexural stiffness of slab units (EI) is assumed being constant in the transverse direction.

$$
F_{m i}=\frac{M_{i}}{\sum_{i=1}^{5} M_{i}} \times 100
$$

where, $F_{m i}$ is moment load distribution factor (\%) for $i$-th unit and $M_{i}$ is the average moment of $i$-th unit.

$$
F_{d i}=\frac{\delta_{i}}{\sum_{i=1}^{5} \delta_{i}} \times 100
$$

where, $F_{d i}$ is displacement load distribution factor (\%) for $i$-th unit and $\delta_{i}$ is the average displacement of $i$-th unit.

Table 1 shows the percent load carried by each of slab units according to Eq. (3). In the case of edge loading, one edge unit (E1 in Table 1) carries about $40 \%$ of the applied load, while for centre loading the value decreases to approximately $25 \%$. Because there are no big differences between deflection and moment distribution factors as shown in Table 1, deflection distribution factors are used in this study to present transverse load distribution factors.

Load distribution factors for linear loads and point loads in centre are given as graph in CEN TC report ${ }^{8}$ based on the theory
Table 1 Comparison of moment and deflection load distribution factors.

\begin{tabular}{c|c|c|c|c}
\hline \multicolumn{2}{|c|}{ Cases } & Moment $\left(F_{m}\right)$ & Deflection $\left(F_{d}\right)$ & Ratio $\left(F_{m} / F_{d}\right)$ \\
\hline \hline \multirow{4}{*}{ Centre } & $\mathrm{C} 3$ & 27.02 & 26.34 & 1.02 \\
\cline { 2 - 5 } & $\mathrm{C} 2, \mathrm{C} 4$ & 21.43 & 21.78 & 0.98 \\
\cline { 2 - 5 } & $\mathrm{C} 1, \mathrm{C} 5$ & 15.05 & 15.06 & 0.99 \\
\hline \multirow{4}{*}{ Edge } & $\mathrm{E} 1$ & 40.26 & 38.42 & 1.04 \\
\cline { 2 - 5 } & $\mathrm{E} 2$ & 26.34 & 27.41 & 0.96 \\
\cline { 2 - 5 } & $\mathrm{E} 3$ & 16.43 & 16.85 & 0.98 \\
\cline { 2 - 5 } & $\mathrm{E} 4$ & 10.29 & 10.50 & 0.98 \\
\cline { 2 - 5 } & $\mathrm{E} 5$ & 6.68 & 6.81 & 0.98 \\
\hline
\end{tabular}

of elasticity. Those values are compared with the obtained results by this study in Figs. 6 and 7. Load distribution factors obtained by finite element method show good agreement with the values of CEN TC report.

\section{Hollow core slabs with wide in-situ RC joints}

A wide variety of situations are available on sites where insitu joints are cast between hollow core units. These can be either different width of reinforced concrete strips up to $500 \mathrm{~mm}$ or intervals of strips, e.g. at $2.4 \mathrm{~m}$ or $3.6 \mathrm{~m}$ spacing. In this paper, two typical slabs with the spacing of $2.4 \mathrm{~m}$ and $3.6 \mathrm{~m}$ are considered as shown in Fig. 8.

In a similar manner to hollow core units without in-situ reinforced concrete joints, in order to determine load distribution factors for hcu with joints it is necessary to obtain deflection curves for centre and edge loads. Figs. 9 and 10 show deflection curves of slabs with 2,400 mm spacing and 3,600 mm spacing respectively, for central and edge line loads.

From these deflection curves, corresponding load distribution factors can be determined using Eq. (3) and factors in case of span length $6 \mathrm{~m}$ are summarized in Table 2. Due to in-situ reinforced concrete joint, the percent load carried by loaded unit i.e., E1 in edge loads and C3 in central loads, increase in comparison with slab system without concrete joint, while load distribution factors for remote units decrease relatively.

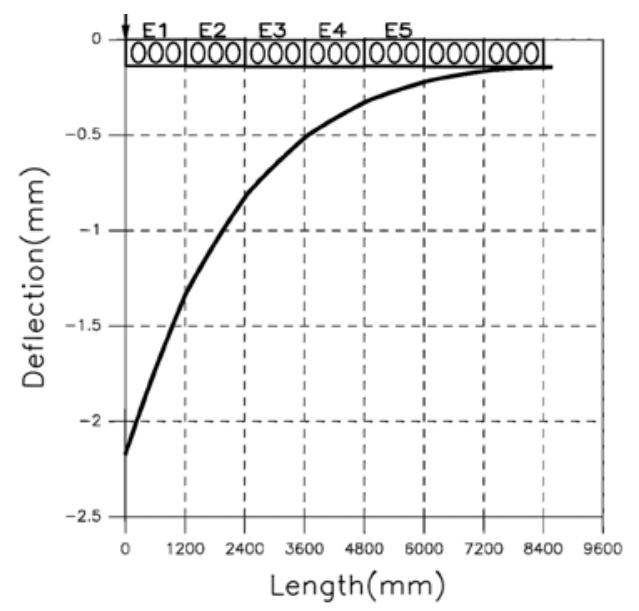

(a) Edge slab

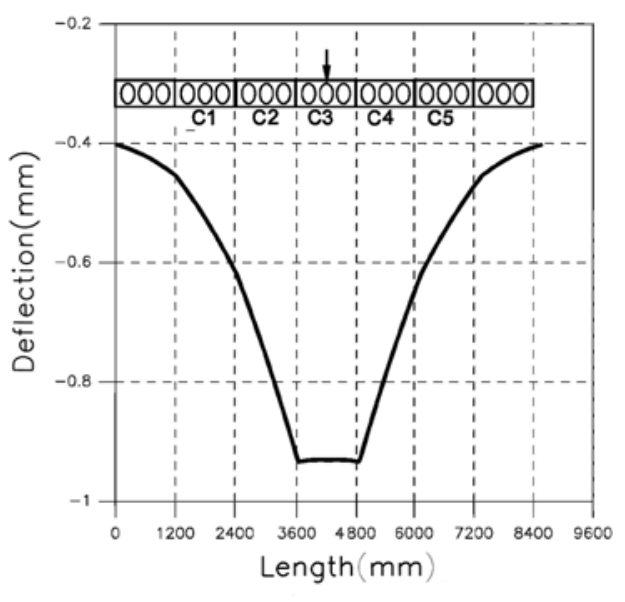

(b) Centre slab

Fig. 5 Deflection curve under line loads. 
Another important factor that has to be considered is the width of in-situ reinforced concrete joints. To consider the effect of width of reinforced concrete joints, three different widths of joints are investigated and load distribution factors according to width of joints are presented in Table 3. In general, as the width of joint increase, the amount of load distribution of loaded unit increase slightly. However, this variation is so small that the influence of joint widths can be ignored for practical purposes.

Also, different Young's modulus of joints are investigated with regard to variation of Young's modulus of in-situ concrete, which is much lower than that of the hollow core unit. From Fig. 11 which shows deflection curves of slab system with different Young's modulus of joint, it was found out that lower Young's modulus of joints cause hollow core units to carry a slight more loads than in-situ reinforced concrete joints. But, this influence on load distribution factors is negligible as shown in Table 4.

\section{Recommendations for design}

Based on the results obtained through numerous parametric studies, a simple design procedure for calculating load distribution factors of hollow core unit with in-situ joints is presented. Figure 12 shows normalized deflection curves of slab system with concrete joints at spacing 2,400 $\mathrm{mm}$ and 3,600 $\mathrm{mm}$ and without concrete joint.

It is remarkable that the normalized deflections within the region where load distribution factors are determined is almost same with those of without concrete joints. It means that the influence of in-situ reinforced concrete joints on load distribution factors is mainly originated from the distance differences due to inclusion of reinforced concrete joints. Therefore, for practical purposes, deflection curves of slab system without reinforced concrete joints can be used to calculate load distribution factors of slabs with joints.

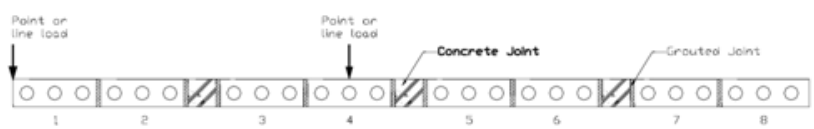

(a) 2,400 mm spacing

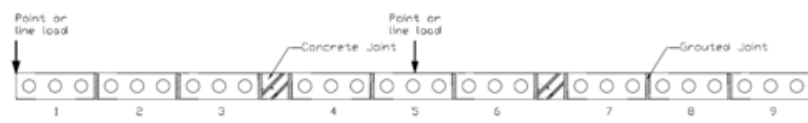

(b) $3,600 \mathrm{~mm}$ spacing

Fig. 8 Pattern of concrete strips.

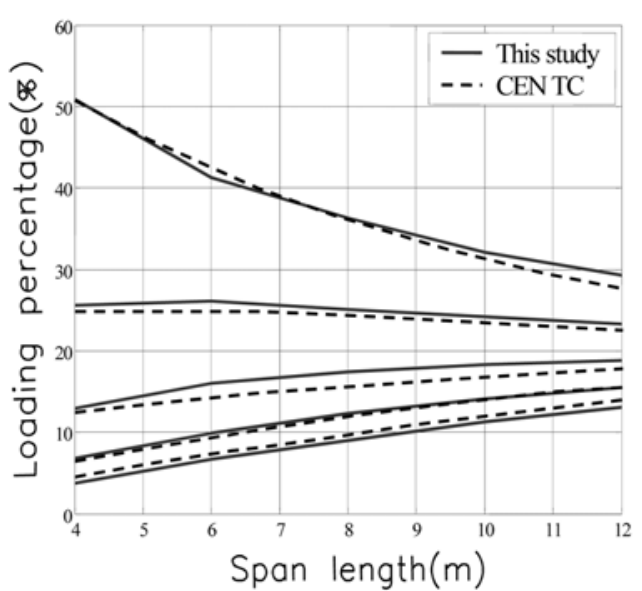

(a) Edge unit loaded

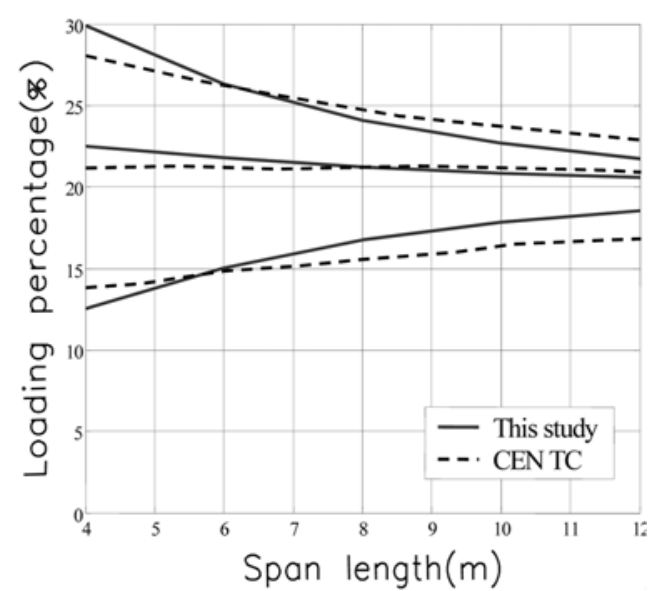

(b) Centre unit loaded

Fig. 6 Load distribution factors for line loads.

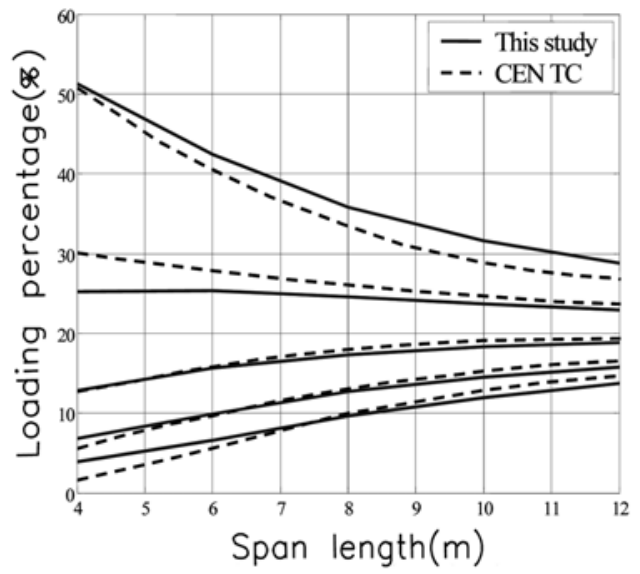

(a) Edge unit loaded

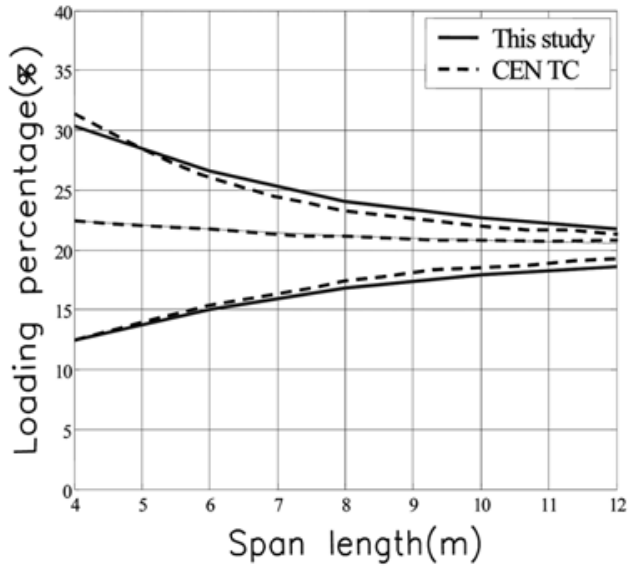

(b) Centre unit loaded

Fig. 7 Load distribution factors for point load. 


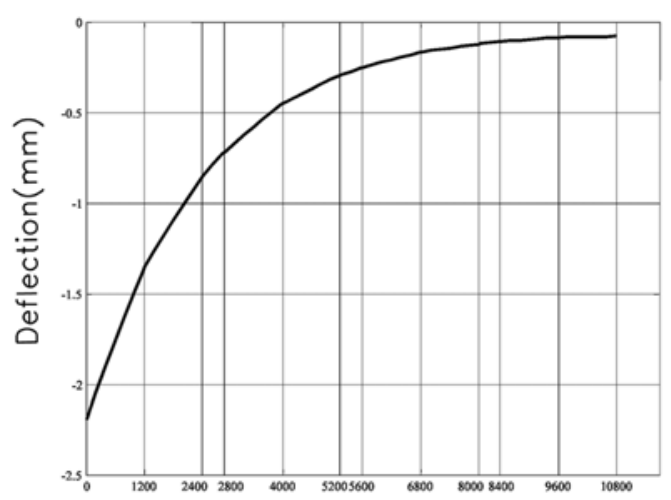

Length $(\mathrm{mm})$

(a) Edge slab

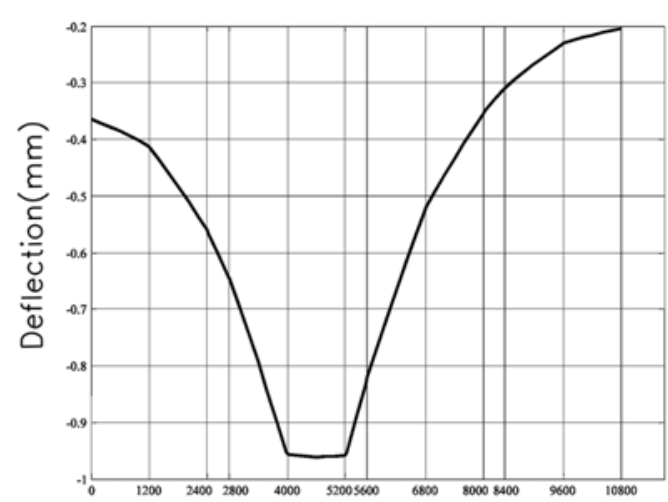

Length $(\mathrm{mm})$

(b) Centre slab

Fig. 9 Deflection curve of slabs with $2,400 \mathrm{~mm}$ spacing.

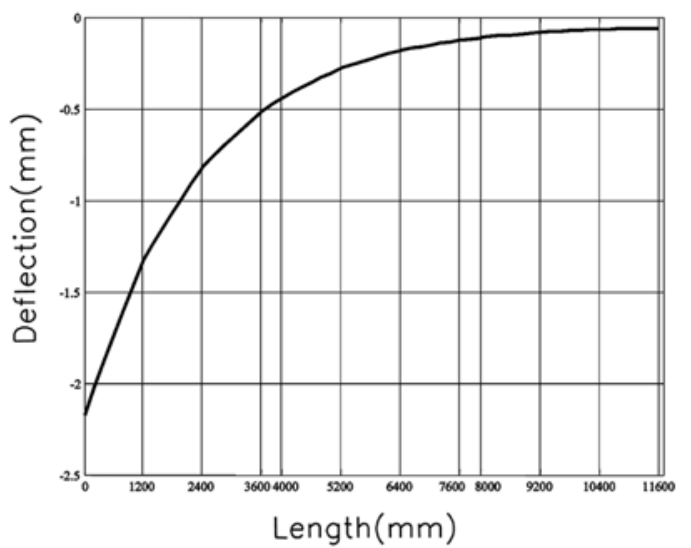

(a) Edge slab

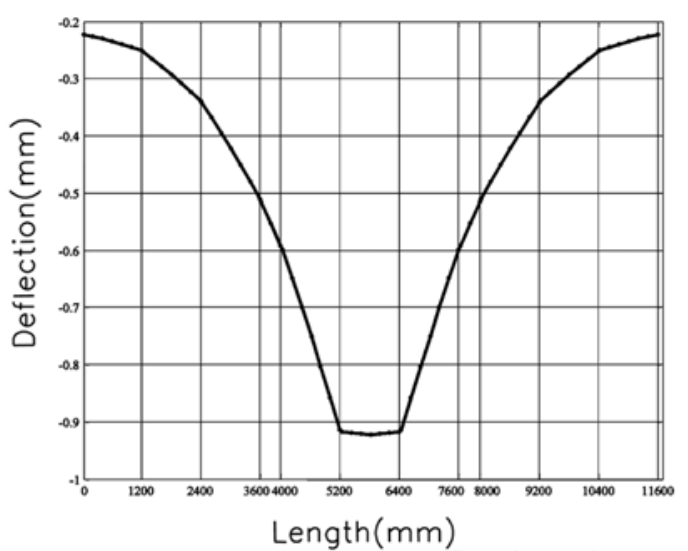

(b) Centre slab

Fig. 10 Deflection curve of slabs with $3,600 \mathrm{~mm}$ spacing.

Table 2 Load distribution factors of slabs with $6 \mathrm{~m}$ span length.

\begin{tabular}{c|c|c|c}
\hline RC joint & $2,400 \mathrm{~mm}$ & $3,600 \mathrm{~mm}$ & without joint \\
\hline \hline $\mathrm{C} 1$ & 14.50 & 12.95 & 15.06 \\
\hline $\mathrm{C} 2$ & 23.76 & 23.00 & 21.78 \\
\hline $\mathrm{C} 3$ & 28.68 & 28.10 & 26.34 \\
\hline $\mathrm{C} 4$ & 20.05 & 23.00 & 21.78 \\
\hline $\mathrm{C} 5$ & 13.01 & 12.95 & 15.06 \\
\hline $\mathrm{E} 1$ & 43.95 & 43.03 & 38.42 \\
\hline $\mathrm{E} 2$ & 27.23 & 26.32 & 27.41 \\
\hline $\mathrm{E} 3$ & 14.46 & 16.32 & 16.85 \\
\hline $\mathrm{E} 4$ & 9.17 & 8.7510 .50 & 10.50 \\
\hline $\mathrm{E} 5$ & 5.20 & 5.58 & 6.81 \\
\hline
\end{tabular}

Table 3 Load distribution factors according to the width of RC joints.

\begin{tabular}{c|c|c|c}
\hline RC joint & $300 \mathrm{~mm}$ & $400 \mathrm{~mm}$ & $500 \mathrm{~mm}$ \\
\hline \hline $\mathrm{C} 1$ & 14.70 & 14.50 & 14.30 \\
\hline $\mathrm{C} 2$ & 23.41 & 23.76 & 24.10 \\
\hline $\mathrm{C} 3$ & 28.25 & 28.68 & 29.10 \\
\hline $\mathrm{C} 4$ & 20.40 & 20.05 & 19.69 \\
\hline $\mathrm{C} 5$ & 13.21 & 13.01 & 12.81 \\
\hline
\end{tabular}

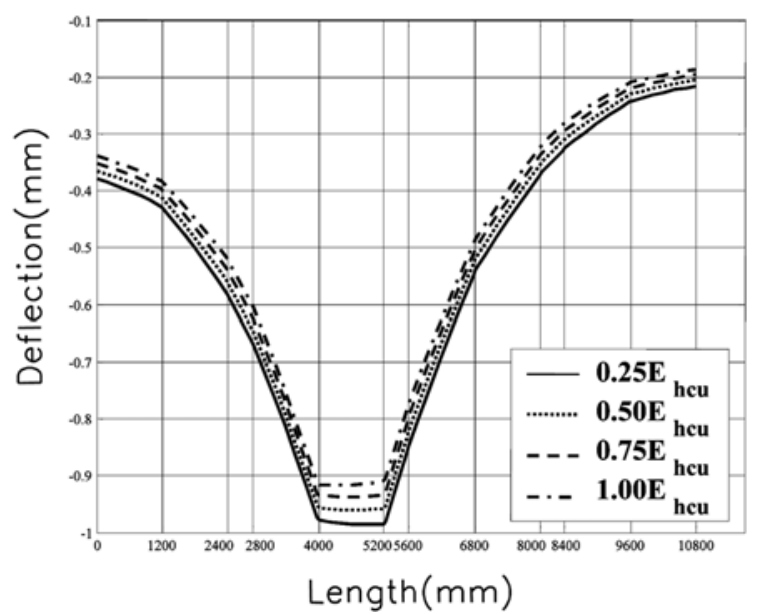

Fig. 11 Deflection curves according to Young's modulus of RC joints.

Figure 13 shows the normalized deflection curves along transverse direction according to different values of span lengths. As shown in this figure, deflection of slab decreases as span length increases. From the viewpoints of load distribution factors, it means that the percentage of loads carried by single loaded unit reduces as span length increases. Once the deflection curves are obtained, then load distribution factors for each unit can be eas- 
Table 4 Load distribution factors according to Young's modulus of joints.

\begin{tabular}{c|c|c|c|c}
\hline CASES & $0.25 \mathrm{E}_{\mathrm{hcu}}$ & $0.50 \mathrm{E}_{\mathrm{hcu}}$ & $0.75 \mathrm{E}_{\mathrm{hcu}}$ & $1.00 \mathrm{E}_{\mathrm{hcu}}$ \\
\hline \hline $\mathrm{C} 1$ & 14.60 & 14.50 & 14.40 & 14.31 \\
\hline $\mathrm{C} 2$ & 23.41 & 23.76 & 23.84 & 23.93 \\
\hline $\mathrm{C} 3$ & 28.49 & 28.68 & 28.85 & 29.03 \\
\hline $\mathrm{C} 4$ & 20.09 & 20.05 & 20.01 & 19.96 \\
\hline $\mathrm{C} 5$ & 13.13 & 13.01 & 12.88 & 12.75 \\
\hline
\end{tabular}

ily calculated using Eq. (3).

In this paper, we suggest deflection curves for edge and centre loads as a function of transverse length $\left(L_{1}\right)$ and longitudinal span length $\left(L_{2}\right)$ by regression analysis. Cubic and quadratic polynomial function was used, for edge and centre deflection curves, respectively as described in Table 5. Coefficients of regression functions according to longitudinal span length are given in Table 6.

As an example of suggested method, load distribution factors for slabs shown in Fig. 14 are calculated. The case considered is a slab with longitudinal span length of $6 \mathrm{~m}$ and $400 \mathrm{~mm}$ in-situ reinforced concrete joints are cast at $2,400 \mathrm{~mm}$ intervals. In order to calculate load distribution factors, at first normalized
Table 5 Regression functions for deflection curves (unit: meter).

\begin{tabular}{c|c|lc}
\hline Location & Edge loads & \multicolumn{1}{|c}{ Centre loads } \\
\hline \hline \multirow{2}{*}{ Function } & $w\left(L_{1}\right)=$ & $w\left(L_{1}\right)=1$ & $; 0 \leq L_{1} \leq 0.6$ \\
& $A L_{1}^{3}+B L_{1}^{2}+C L_{1}+1$ & $w\left(L_{1}\right)=a L_{1}^{2}+b L_{1}+c ; L_{1}>0.6$ \\
\hline
\end{tabular}

Table 6 Coefficients* of regression functions.

\begin{tabular}{c|c|c|c|c|c|c}
\hline$L_{2}(\mathrm{~m})$ & $\mathrm{A}$ & $\mathrm{B}$ & $\mathrm{C}$ & $\mathrm{a}$ & $\mathrm{b}$ & $\mathrm{c}$ \\
\hline \hline 4 & -0.0038 & 0.0709 & -0.4376 & 0.0659 & -0.5159 & 1.2779 \\
\hline 6 & -0.0023 & 0.0479 & -0.3529 & 0.0454 & -0.3745 & 1.2099 \\
\hline 8 & -0.0013 & 0.0322 & -0.2811 & 0.0304 & -0.2611 & 1.1490 \\
\hline 10 & -0.0008 & 0.0255 & -0.2265 & 0.0205 & -0.1821 & 1.1050 \\
\hline 12 & -0.0005 & 0.0163 & -0.1847 & 0.0128 & -0.1213 & 1.0707 \\
\hline
\end{tabular}

(Note)* other values can be obtained by linear interpolation.

deflection curve should be determined. According to Tables 5 and 6 , the deflection curve for this case is:

$$
w(x)=-0.0023 x^{3}+0.0479 x^{2}-0.3529 x+1
$$

hence, the average deflection of each unit is as follows:

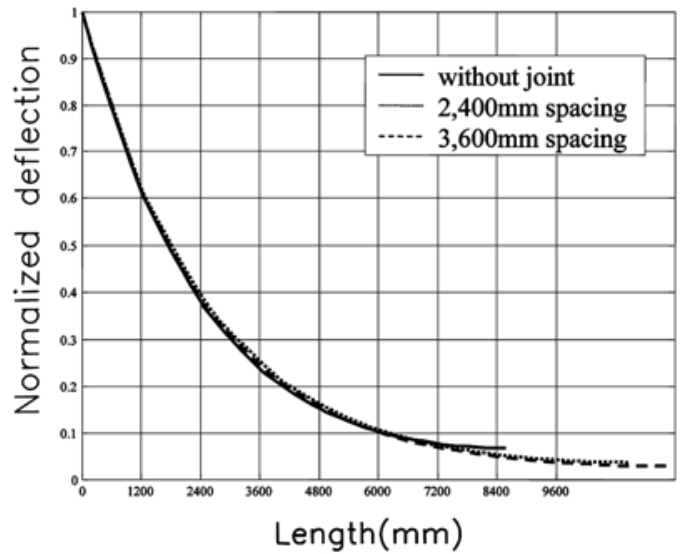

(a) Edge loads

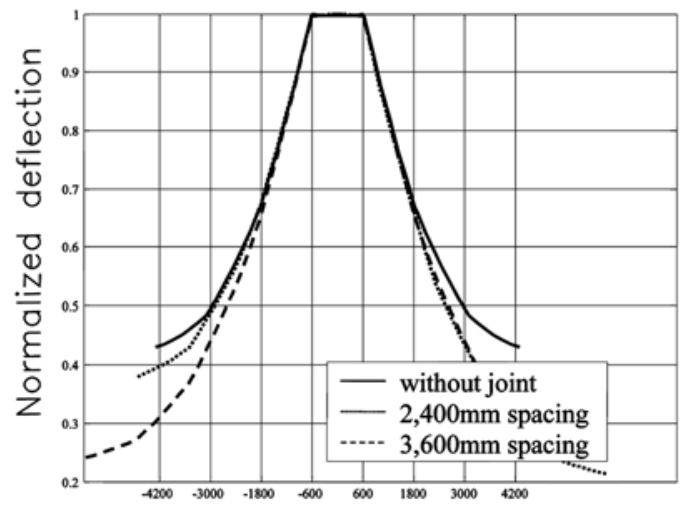

Length $(\mathrm{mm})$

(b) Centre loads

Fig. 12 Normalized deflection curves.

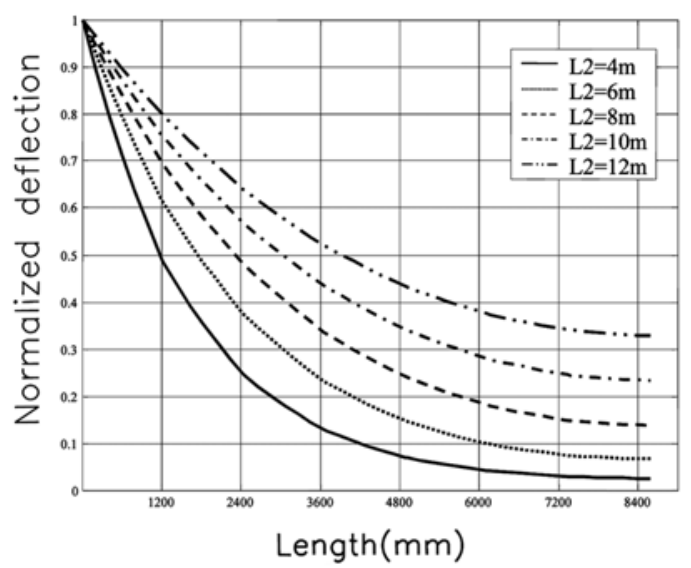

(a) Edge loads

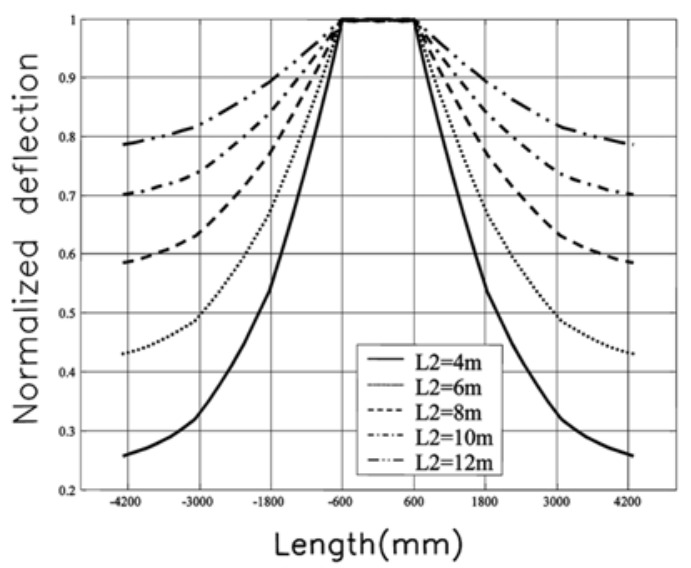

(b) Centre loads

Fig. 13 Normalized deflection curves according to longitudinal span length. 


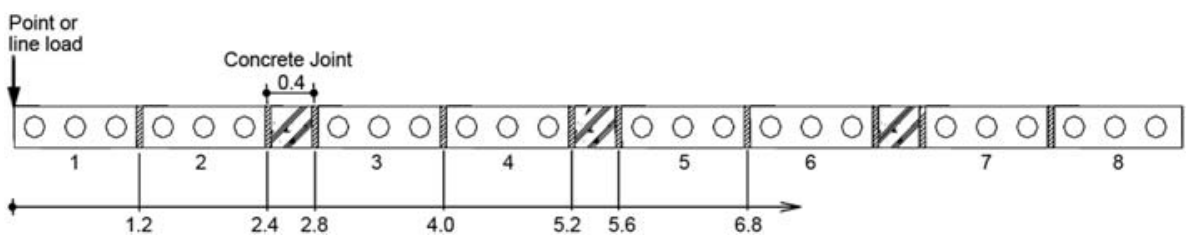

Fig. 14 An example slab system.

$$
\begin{aligned}
& \delta_{1}=\frac{1}{1.2} \int_{0}^{1.2} w(x) d x=0.8103, \quad \delta_{2}=\frac{1}{1.2} \int_{1.2}^{2.4} w(x) d x=0.5108 \\
& \delta_{3}=\frac{1}{1.2} \int_{2.8}^{4.0} w(x) d x=0.2664, \quad \delta_{4}=\frac{1}{1.2} \int_{4.0}^{5.2} w(x) d x=0.1683 \\
& \delta_{5}=\frac{1}{1.2} \int_{5.6}^{6.8} w(x) d x=0.1058
\end{aligned}
$$

Therefore according to Eq. (3), load distribution factors for unit 1 is:

$$
\begin{aligned}
& F_{1}=\frac{\delta_{i}}{\sum_{i=1}^{5} \delta_{i}} \times 100= \\
& \frac{0.8103}{0.8013+0.5108+0.2664+0.1683+0.1058} \times 100=43.53 \%
\end{aligned}
$$

in the same manner, $F_{2}=27.44 \%, F_{3}=14.31 \%, F_{4}=9.04 \%$, and $F_{5}=5.68 \%$. These values show good agreement with those obtained by complicated finite element analysis in Table 2 .

\section{Conclusions}

Load distribution factors for hollow core units with reinforced concrete joints under line loads and point load were determined from the deflection curves obtained by finite element methods in this study. The results are summarized as the following.

1) Load distribution factors calculated from the deflection curves obtained by FEM shows good agreement with previous results, such as, FIB and CEN data.
2) Because there are small differences in load distributions for point load and line loads, same load distribution factors can be used for any type of loads, i.e., point load or line loads, for design purposes.

3) The inclusion of RC joint causes reduction of load distribution for remote units because distance to the remote units from the point of load is increased, while the portion of load distribution carried by loaded unit increases.

4) From the deflection curves suggested as polynomial functions by regression analysis, load distribution factors for hollow core units with any type of RC joints can be easily calculated. In the future, experiments on the load distribution factors for hollow core units with reinforced concrete joints will be performed.

\section{References}

1. SAP 2000, Computers \& Structures Inc., 2001.

2. Stanton, J., "Proposed Design Rules for Load Distribution in Precast Concrete Decks," ACI Structural Journal, 1987, pp. 371 382.

3. Van Acker, A., "Transversal Load Distribution of Linear Loading in Hollow-Core Floors," FIP Conference, Calgary, Canada, Vol. 3, 1984, pp. 27 49.

4. European Standard EN1168:2005, Precast Concrete ProductsHollow Core Slabs, British Standards Institution, London, 2005.

5. Venkateswarlu, B., et al., "Roof and Floor Slabs Assembled with Precast Concrete Hollow Core Units," ACI Journal, Vol. 79, No. 6, 1982, pp. 50 55.

6. O'Brien, E. J. and Keogh, D. L., "Upstand Finite Element Analysis of Slab Bridges," Computers \& Structures, Vol. 69, 1998, pp. $671 \sim 683$.

7. Federation Internationale de la Precontrainte, Precast Prestressed Hollow Cored Floors, FIP Recommendations, Thomas Telford, London, 1967.

8. CEN TC 229, Floors of Precast Prestressed Hollow Cored Elements, European Committee for Standardization, 1995. 